\title{
Atlantis
}

Critical Studies in Gender, Culture \& Social Justice

Études critiques sur le genre, la culture, et la justice

\section{Free Speech Rhetoric and Normalizing Violence: Setting Higher Standards for University Guest Speaker Policies}

\section{Madison McDonald}

Volume 41, Number 1, 2020

URI: https://id.erudit.org/iderudit/1074014ar

DOI: https://doi.org/10.7202/1074014ar

See table of contents

Publisher(s)

Mount Saint Vincent University

ISSN

1715-0698 (digital)

Explore this journal

Cite this article

McDonald, M. (2020). Free Speech Rhetoric and Normalizing Violence: Setting Higher Standards for University Guest Speaker Policies. Atlantis, 41(1), 34-45. https://doi.org/10.7202/1074014ar
Article abstract

In response to recent protests against controversial guest speakers, many Canadian universities have implemented new policies that conflate academic freedom and freedom of speech. The resultant free speech policies often protect speakers regardless of the content of their speech; this paper discusses the importance of barring speech that normalizes acts of harm.
All Rights Reserved (C Madison McDonald, 2020

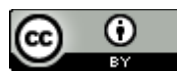

This document is protected by copyright law. Use of the services of Erudit (including reproduction) is subject to its terms and conditions, which can be viewed online.

https://apropos.erudit.org/en/users/policy-on-use/ 


\section{Free Speech Rhetoric and Normalizing Violence: Setting Higher Standards for University Guest Speaker Policies}

Madison McDonald is a recent graduate of McMaster University's Gender Studies and Feminist Research M.A. program. Her recent research focuses on anti-feminist women and their unique relationship to far-right politics.

Abstract: In response to recent protests against controversial guest speakers, many Canadian universities have implemented new policies that conflate academic freedom and freedom of speech. The resultant free speech policies often protect speakers regardless of the content of their speech; this paper discusses the importance of barring speech that normalizes acts of harm.

Keywords: academic freedom, alt-right, freedom of speech, guest speaker policies, no-platforming, university policy
$\mathbf{R}$ ecent protests against controversial guest speakRers have reignited debates about freedom of speech on Canadian university campuses, raising the question: what restrictions - if any-should there be on campus speech? Many defenders of free speech oppose viewpoint-based speech restrictions, while others justify speech restrictions as a harm-prevention measure and insist that certain speakers be refused a platform entirely, a move sometimes referred to as 'no-platforming' (Levy 2019). A major challenge facing proponents of no-platforming is the lack of a clear and consistent understanding of exactly which types of speech should be considered seriously harmful (and therefore be refused a platform). Free speech advocates accordingly critique harm-based restrictions on the grounds that ethical limitations on speech become arbitrary when they fail to follow a consistent principle (Heinze 2018, 94). According to this criticism, restrictions on free speech risk being applied inconsistently at best and become tools for political gain at worst.

Though there are varied understandings of what ought to be considered 'seriously harmful,' this paper outlines one discernable type of speech that causes unquestionable harm and therefore should be restricted from campus platforms: speech that normalizes acts of violence. The first two sections of this paper discuss major themes in current debates about campus free speech and seeks to clarify points of ambiguity. After outlining the ethical, epistemic, and academic values underpinning both support for and opposition to no-platforming, I closely examine the meaning of harm. 'Harm' is frequently referenced in free speech debates, yet often remains ambiguously defined (when defined at all); in order to minimize confusion and inconsistency, I propose a clear and nuanced definition of harm to inform no-platforming decisions. The following two sections propose 
specific criteria with which to assess university guest speaker policies, grounded through recent examples of controversial speakers and new campus free speech policies. I outline a framework for identifying speech that normalizes acts of violence, which I describe as bridging rhetoric. I ground this terminology with examples, including trends in heteroactivist, far-right, and alt-right discourses that strategically conflate anti-LGBTQ+ and free speech rhetoric. To ground my proposed framework for campus speech restrictions, I examine a recent case of no-platforming at McMaster University. Though Jordan Peterson has been invited to speak at several Canadian universities, the McMaster University case is examined here due to the immediate policy outcome triggered by his campus visit in March 2017. Persistent protests against Peterson's appearance at the University ultimately blocked the speaking event from proceeding, circumstances that spurred the creation of new Freedom of Expression (FOE) policies and outlining what would thereafter be considered acceptable forms of protest according to the University. Informed by a close look at McMaster's updated FOE guidelines, I argue that campus free speech policies should go beyond the legal limits on free speech. I propose restrictions on campus free speech that respect both academic freedom and an ethical responsibility to the safety of all community members. I do not claim that controversial or objectionable viewpoints should never be given a platform for fear of causing offence. Rather, I argue that reasonable limitations on campus speech should include restrictions on speech that crosses the line from offensive to normalizing violence and that thoughtful discussions of campus speaker policies should discern between the two. As university campuses are increasingly key sites where equity politics are debated (Nash, Gorman-Murray, and Browne 2019), it is essential to nuance the campus free speech debate in order to meaningfully resist oppressive ideologies.

\section{The Campus Free Speech Debate}

The free speech debate is often framed as a clash of epistemic reasoning against an ethical obligation to harm-prevention. When a speaker is known to promote hate, prejudice, or otherwise violent ideologies, protestors may demand a disinvitation from the institutions, also referred to as 'no-platforming.' More specifically, no-platforming is the attempt to deny a platform to speech that will harm some or all of the audience (Levy 2019, 2) and has become an important consideration in university free speech debates. For the purposes of this paper, I use no-platforming and speech restrictions interchangeably to refer to viewpoint-based platform refusals and disinvitations.

Contemporary defenders of no-platforming justify their position as one of harm-prevention, where harm can refer to a range of outcomes: the proliferation of further bias arising from biased speech and harmed dignity (Ben-Porath 2019); the reinforcement of unjust social hierarchies (Simpson 2013); and an increased threat of violence for groups targeted by hate speech (O'Keefe 2016). Critics of no-platforming object to harm-based restrictions for a number of reasons. Given the fundamental importance of free speech rights to a liberal view on democracy, some argue that restrictions on freedom of speech pose a threat to democratic health. Heinze $(2018,88)$ argues that any ban on speech based solely on viewpoint-selective grounds is "always inherently anti-democratic, even when adopted on legitimate security grounds." While for some, speech restrictions based on legitimate security grounds may not be sufficiently justified, other defenders of free speech concede that harmbased restrictions are justified in certain cases. The liberal conception of free speech promotes the expression of ideas and opinions without coercive institutional censorship, with the exception of speech that is "seriously harmful or carries an imminent risk of harm” (Simpson and Srinivasan 2018, 191). The principal criticism of harm-based restrictions according to the liberal perspective, then, is not that they are inherently unjustified, but that the criteria for determining what types of speech are considered seriously harmful is flawed. One charge against harm-based speech restrictions is that they include speech that is merely offensive or not considered politically correct, neither of which ought to be considered seriously harmful according to this view. This line of argument, also referred to as the 'right to offend,' is frequently employed in debates about academic freedom, itself a reflection of the broader free 
speech debate. Offence, it is argued, is not reflective of a speech's quality but instead characterizes the listener's reaction and, "the mere fact that what I say causes someone offence is not a sufficient reason to forbid me to say it" (Barrow 2009, 187).

Defenders of free speech also appeal to epistemic reasoning, arguing that in the pursuit of truth, the strength of one's argument can only be proven by encountering and refuting the views of one's opponents. Especially in the context of the university learning experience, exposure to divergent perspectives through free and open dialogue presents the opportunity to reassess one's own beliefs in the face of evidence-based arguments (Ceci and Williams 2018, 314). Stripping universities of all potentially offensive speech, it is argued, denies students the opportunity to practice defending their ideas and encourages them to claim they have been offended anytime their views are challenged (Dunt 2015).

Levy (2019) argues that though the campus free speech/no-platforming debate has been largely regarded as pitting appeal to reason against the duty to prevent harm and other values, there has been a recent turn to epistemically-based defences of no-platforming. Simpson and Srinivasan (2018) argue that in the context of the university, both defenders and critics of no-platforming mistakenly treat the debate as if it were about freedom of speech when it is more accurately an issue of academic freedom. By virtue of being a specialized institution (governed by principles of academic freedom), content-based restrictions are already ubiquitous in universities (Simpson and Srinivasan 2018). In addition to legal limitations on free speech, the university's commitment to academic freedom imposes restrictions on speech that are different from those that apply to the general public.

According to the 2011 Statement on Academic Freedom, adopted unanimously by Canadian university presidents, academic freedom is "the freedom to teach and conduct research in an academic environment ... [and] includes the right to freely communicate knowledge and the results of research and scholarship" (Universities Canada 2011). The Statement explicitly distinguishes academic freedom from other iterations of free speech rights: "Unlike the broader concept of freedom of speech, academic freedom must be based on institutional integrity, rigorous standards for enquiry and institutional autonomy" (Universities Canada 2011). Additionally, academic freedom must be grounded in reasoned discourse and scholarly rigor, and is additionally constrained by professional disciplinary standards (Universities Canada 2011). Based on the criteria dictated by academic freedom, free speech on Canadian university campuses is already restricted based on epistemic quality.

If university administration and faculty are committed to academic freedom, do the same standards apply to guest speakers on campus? Though singular instances of speakers who base their claims on poor scholarship will not define the integrity of a given department, Simpson and Srinivasan argue that "the overall intellectual and disciplinary culture of a university is shaped by all of the public speaking activities that happen within the institution" $(2018,200)$. In order to take its epistemic purposes seriously, the university is justified in refusing a platform to speakers who do not meet disciplinary standards or ground their arguments in rigorous scholarship.

While in some instances it will be evident whether a speaker adheres to the academic standards, certain cases cannot be so easily determined. Disagreement about professional standards occurs both across and within disciplines; the resulting discord creates borderline cases in which it is unclear if no-platforming can be justified on epistemic grounds. Opinions about which topics are inappropriate for academic inquiry, which linguistic conventions are no longer acceptable, or whether a particular epistemic debate is settled or remains contested may differ amongst scholars and create disagreement about which disciplinary standards ought to inform speech restrictions.

The recent controversy surrounding Rebecca Tuvel's 2017 article "In Defense of Transracialism" is a prime example of both interdisciplinary and intradisciplinary rifts over professional standards. Tuvel's article was published in April 2017 in Hypatia: A Journal of Feminist Philosophy, and draws parallels between transgender and transracial identities; Tuvel argues that the 
increasing acceptance of sex and gender transitions should likewise apply to racial transitions and include support for individuals who wish to assert a racial identity that differs from their birth (2017). Tuvel refers to Rachel Dolezal's self-presentation as Black (despite being born a white woman) as an entry point for her discussion, contrasting the widespread backlash against Dolezal's transracial identity and the more supportive public reception of Caitlyn Jenner's transgender identity. The publication sparked a frenzy of reactions, receiving both virulent criticism and support from scholars and the broader media. Critics claimed that the article included "egregious levels of liberal white ignorance and discursive transmisogynistic violence" (quoted in McKenzie, Harris, and Zamudio-Suaréz 2017), while supporters argued that the vicious attacks directed at the author were akin to a "modern-day witch hunt" (Singal 2017) and reflected the current "era of outrage" (Oliver 2017). The Hypatia staff themselves were divided in the wake of the erupting controversy. In the days following the article's release, an apology signed on behalf of the "majority of associate editors" was posted on Facebook, avowing that " $[c]$ learly, the article should not have been published" (quoted in McKenzie, Harris, and Zamudio-Suaréz 2017). Hypatia's editor-in-chief, Sally Scholz, along with the journal's board of directors, defended the decision to publish Tuvel's article, with Scholz publicly affirming a belief that "Hypatia should publish on a wide array of topics employing a wide array of methodologies" (quoted in Weinberg 2017b). Philosophers were in similar disagreement about the article. An open letter signed by hundreds of academics, including philosophers Alexis Shotwell, Lori Gruen, and Shannon Winnubst, called for the article's retraction. The letter claims Tuvel's work falls short of scholarly standards, listing four principal criticisms including the use of language not in alignment with current academic conventions (such as deadnaming) and a failure to sufficiently engage with scholarly work by women philosophers of colour (Singal 2017). Other philosophers defended Tuvel: in a post on philosophy site The Daily Nous, academic Justin Weinberg claimed that the criticisms listed in the open letter were "plain false," unclear, or insufficient (Weinberg 2017a). Academics outside the philosophical discipline were also divided in the debate over scholarly standards. Suzanna Danuta Walters, editor of Signs: Journal of Women in Culture and Society and professor of sociology, condemned Hypatia's associate editors for both insulting Tuvel and undermining the peer review process. Blaming toxic academic call-out culture for the widespread condemnation of Tuvel's article, Danuta Walters defends Tuvel's work as that of a committed feminist philosopher on the side of "progressive social justice” (Danuta Walters 2017). The deep rifts amongst academics in their responses to Tuvel's article shows that consensus on scholarly conventions cannot be taken for granted and therefore cannot be the sole basis for determining campus speech restrictions.

Epistemic standards can certainly serve as a starting point for creating campus speech restrictions, however, borderline cases may not be readily settled by this criterion alone. Rather than using epistemic or harm-prevention criteria, I argue that there is value in considering both when creating campus speech guidelines. In an effort to maintain the university's intellectual and disciplinary culture, guest speakers on campuses should, at minimum, meet the standards of reasoned argument and rigorous research set out by academic freedom. In controversial cases, especially those involving disputes over whether a speaker adheres to disciplinary standards, I believe that there is still value in using harm-prevention criteria to guide platforming decisions.

\section{Defining Harm}

What harms are being referenced by harm-based speech restrictions? The most powerful speech restrictions in Canada are the legal boundaries on speech defined by the Criminal Code of Canada. Subsection 319 of the Criminal Code prohibits hate propaganda (also referred to as hate speech), which includes the public incitement of hatred against an identifiable group "where such incitement is likely to lead to a breach of the peace." Though campus speech policies must abide by these legal restrictions, these boundaries on speech are not enough. University guest speaker policies must additionally refuse platforms to speech that normalizes acts of violence given its ability to reinforce systemic oppression. In an attempt to clarify exactly what speech these restrictions refer to, I will 
define "acts of violence" using intentional misgendering as a timely example of normalizing harm. Misgendering can refer to addressing someone by the incorrect gender pronoun or denying someone access to their preferred gendered space, including washrooms (McLemore 2015, 53). While misgendering can certainly happen accidentally or unintentionally, I will explain why intentional misgendering is an act of violence.

In their 2002 "World Report on Violence and Health," the World Health Organization defines violence as "the intentional use of physical force or power, threatened or actual, against oneself, another person, or against a group or community, that either results in or has a high likelihood or resulting in injury, death, psychological harm, maldevelopment or deprivation" (Krug et al. 2002, 5). The authors explicitly remark on their decision to define violence broadly and include non-physical forms of violence: "This [definition] reflects a growing recognition among researchers and practitioners of the need to include violence that does not necessarily result in injury or death, but nonetheless poses a substantial burden on individuals, families, communities and health care systems worldwide" (Krug et al. 2002, 5). Acts of violence can therefore refer to include both physical and nonphysical threats, including psychological violence.

Intentionally misgendering trans people is a form of psychological violence. Riley J. Dennis outlines the psychological effects that misgendering has on trans people:

[Misgendering is] a way of invalidating their identity. It makes them feel disrespected, isolated, and uncomfortable, and hated simply because of their gender. It tells them that they should hide who they really are, that people will never fully accept them. Misgendering a trans person causes real psychological harm. (Dennis 2017, 2:29-2:43)

In a study on trans experiences of misgendering, McLemore found that the highest proportion of participants $(34.8 \%)$ reported feeling very stigmatized when they were misgendered $(2015,57)$. Misgendering not only causes psychological harm, but also affects an individual's physical wellbeing. Misgendering is known to cause anxiety and can lead to significant distress, causing harm that, over time, can lead to suicide (Daley 2017); statistics from the Canadian Mental Health Association report that $77 \%$ of trans respondents in an Ontario-based survey had seriously considered suicide and $45 \%$ had attempt suicide (“Trans Mental Health" n.d.). Describing the impact that repeated misgendering has on their life, one genderqueer person discloses, "I felt erased, I felt like the message that I consistently got was 'you don't exist,' and for me that line between you don't exist and you shouldn't exist can feel pretty similar a lot of the times" (Bown-Kai quoted in Daley 2017). Given the effects of misgendering on the lives and wellbeing of trans and gender variant individuals, repeated intentional misgendering is unquestionably an act of violence. In the following section, I use this understanding of violence to inform a case for restrictions on seriously harmful speech; more specifically, speech that covertly normalizes acts of violence. I use intentional misgendering as an entry point to discuss broader trends amongst heteroactivists and the far-right to normalize violent discourse. Using freedom of speech rhetoric, speakers create a rhetorical bridge from anti-LGTBQ+ ideologies to a defense of democratic rights, implicitly justifying their oppressive stance. I propose the term "bridging rhetoric" can be used to identify this particular type of harmful speech; additionally, I argue that bridging rhetoric as a framework can subsequently inform decisions about which types of speech are permissible on university campuses.

\section{Shifting the Debate: Bridging Rhetoric}

Though certain types of oppressive speech may be easily recognized, in most cases harmful speech is more challenging to definitively discern. In order to resist harmful ideologies, one must be able to identify them and suitable language is required to do so. Explicit threats and slurs can be clearly categorized as harmful; however, implicit oppression may need a more nuanced framework for assessment. Violent ideologies are sometimes reframed within more widely accepted discourses, a type of oppressive speech that I refer to as bridging rhetoric. Rather than defend an act of violence outright, bridging rhetoric covertly normalizes 
acts of violence by aligning them with broader social norms. Consider Jordan Peterson's stance on personal pronouns as an example. The University of Toronto psychology professor gained notoriety in September 2016 for his three-part YouTube series called "Professor against political correctness," created in response to the University's new mandatory anti-bias training and a federal amendment to add gender identity and expression to the Canadian Human Rights Act (Lynskey 2018). Peterson states that his principal concern with the amendment is the requirement to address people by the pronouns of their choosing; this "compelled speech" is part of what Peterson calls a "radical collectivist left-wing game" in which compassion is used as a guise to "gain linguistic supremacy in the area of public discourse" (Peterson 2018, 2:00-2:23). Rather than taking an explicitly anti-trans position, Peterson uses free speech rhetoric and claims about his own linguistic rights to justify intentional misgendering. In a CBC interview, when asked about referring to his trans nonbinary colleague using the correct pronouns, Peterson responds,

The mere fact that Professor Peet would like to be addressed by a particular pronoun does not mean that I am required to address him [sic] by that pronoun. That doesn't mean that I deny his [sic] existence or the existence of people who don't fit neatly in binary gender categories. I reserve the right to use my own language. (Peterson 2016)

Peterson strategically frames his resistance as a defence of his own democratic rights and sidesteps further comment on the harm that misgendering causes trans people. Peterson does not justify misgendering as an act of violence but positions himself instead as a defender of free speech, which, in Peterson's words, "is not just another value [but] the foundation of Western civilization" (quoted in Murphy 2016). Peterson bridges a discursive gap to present his arguments from a normatively acceptable position: using free speech rhetoric, Peterson reframes his arguments away from a defence of harm (a more challenging stance to take in Canada, where overt violence conflicts with the state's peaceful self-image) and toward a defence of democratic rights (which are protected by law in the Canadian Charter of Rights and Freedoms).
Peterson's reframing is characteristic of a broader trend in anti-LGBTQ+ resistive discourses: Nash, GormanMurray, and Browne (2019) argue that heteroactivists in Canada, Australia, and Great Britain-Peterson included-increasingly frame their oppressive discourses as claims to freedom of speech and freedom of religion. Heteroactivists, who seek to resist LGBTQ+ equalities and re-inscribe heteronormative gender relations, reposition their arguments within seemingly intellectual debates about rights, rather than making morality-based claims against LGBTQ+ equalities (Nash, Gorman-Murray, and Browne 2019). By reframing the debate and employing bridging rhetoric, anti-LGBTQ+ discourses are grounded within claims about freedom of speech; in the case of intentional misgendering, shifting the debate away from attacks on trans rights and towards broader free speech debates functions to normalize this particular act of violence.

Though Nash, Gorman-Murray, and Browne (2019) remark that heteroactivist discourses are taken up by individuals and groups across the political spectrum, the co-optation of rights rhetoric and claims of harm is also a tactic commonly employed by the far-right and alternative right, or "alt-right." Lyons defines the altright as:

[A] loosely organized far-right movement that shares a contempt for both liberal multiculturalism and mainstream conservatism; a belief that some people are inherently superior to others; a strong internet presence [...] [it] combines White nationalism, misogyny, antisemitism, and authoritarianism in various forms. $(2017,2)$

When their inflammatory speech is denied a platform, alt-right and far-right speakers claim that their free speech rights have been infringed upon, co-opting freedom of speech rhetoric from leftists as a shield -following a similar pattern as the aforementioned heteroactivist discursive strategy. In 2017, Milo Yiannopoulos, right-wing provocateur and former editor at alt-right outlet Breitbart News, was scheduled to speak at University of California, Berkeley until protests caused his talk to be cancelled. Yiannopoulos is known for making incendiary remarks against trans people, Muslims, Black Lives Matter activism, feminism, and queer people and writing columns with titles such as 
"Birth Control Makes Women Unattractive and Crazy" and "Would You Rather Your Child Had Feminism or Cancer?” (BBC News 2017). Following the cancellation of his talk, Yiannopoulos was quick to frame the incident as an attack against freedom of speech, claiming that "the Left is absolutely terrified of free speech and will do literally anything to shut it down" (quoted in Dearden 2017). Much like the way Peterson sidesteps discussions about harm-prevention in favour of debating democratic freedoms, Yiannopoulos strategically shifts the conversational focus away from his own inflammatory rhetoric and instead frames himself as a victim of leftist politics. In doing so, the discussion is no longer about far-right violence, focusing instead on a seemingly worthy debate about free speech.

This rhetorical defense is often referred to as the 'weaponization of free speech,' in which free speech and freedom of expression discourse is used to justify bigotry and white supremacy (Picazo 2017; Scott 2020; Zine 2018). This is particularly relevant to Canadian universities, as campuses have increasingly become targets for alt-right recruitment. In 2017, the $\mathrm{CBC}$ reported a rise in right-wing populist paraphernalia on university campuses across the country, promoting a "White Students Union" and displaying far-right references, slogans like "Make Canada Great Again" (Zhou 2017). In November 2016, posters were found around the McMaster University campus that included links to alt-right websites and messages such as "Tired of Anti White propaganda? You are not alone" (Hastie 2019).

Using similar freedom of expression discourse, altright speakers are invited to university campuses under guises of free and open inquiry. In 2018, alt-right figure Faith Goldy was invited by the Laurier Society for Open Inquiry to present a talk titled "Ethnocide: Multiculturalism and European Canadian Identity" at Wilfred Laurier University (Paradkar 2018). Goldy has said the 'Fourteen Words' neo-Nazi slogan on-air and was fired from Rebel Media after appearing on a white nationalist podcast during the 2017 Charlottesville riots (Brean 2019; Canadian Anti-Hate Network 2018). When asked about her decision to invite Goldy, the Society's co-founder and president Lindsay
Shepherd told the CBC, "These views are out there no matter how despicable some people find them. Actually, the best thing to do is air them out and let them be publicly challenged" (quoted in Lam and Bueckert 2018). There is a significant difference, however, between challenging racist and xenophobic views and providing those views with a platform. No matter how the invitation to speak is justified, the very fact of the invitation suggests that the speaker's ideas are worthy of debate. Challenging hate is essential to the pursuit of a more equitable society, nevertheless, providing platforms for harmful or violent viewpoints is not necessary to challenge them.

Freedom of speech rhetoric is used as a shield to protect the alt-right's overt racism and bigotry and is likewise employed by heteroactivists to more covertly normalize acts of violence. Though the two groups may share some values and not others, both the altright and anti-LGBTQ+ rights advocates oppose advances in equity for marginalized groups. I propose that bridging rhetoric can be used as a term to identify speech that co-opts free speech discourse as a cover for normalizing violence. As demonstrated above, both groups see Canadian university campuses as viable platforms for their violent and harmful discourse. In light of these examples, I will now examine McMaster University's policies as a case study and discuss why it is imperative that campus speech restrictions go beyond the limits required by law.

\section{Bridging Rhetoric and University Speech Policies}

McMaster University's "Freedom of Expression: Frequently Asked Questions" (FAQ) webpage outlines the institution's current restrictions on free speech. The page references the legal boundaries on speech set out by the Criminal Code of Canada and the Ontario Human Rights Code, as well as the University's own "Policy on Discrimination and Harassment" which requires "all members of the University community" to "respect the rights and freedoms of others" (McMaster n.d.). According to the FAQ page, all members of the McMaster community are free and encouraged to invite speakers, with no further restrictions on the kinds of speech that are permitted. The page explicitly states 
that the University administration does not endorse the views of invited speakers and that, while they do not tolerate hate speech, McMaster is "committed to freedom of expression" and does not shut down unpopular or controversial speaker events (McMaster n.d.).

One such event was Jordan Peterson's invitation to speak at the University in 2017. Although Peterson was met with chanting and musical fanfare upon his arrival to the McMaster University Campus, it was not a celebratory reception. Peterson was scheduled to appear as part of a panel debate about free speech and political correctness in academic settings; however, protestors' persistent sonic disruptions ultimately prevented him from speaking (Beatty 2017). In the wake of Peterson's visit to campus, McMaster formed a committee on protest and freedom of expression and created a new document outlining what the University deems to be acceptable methods of protests against guest speakers and freedom of expression guidelines. The University's "Freedom of Expression, Protest and Dissent: Guidance for Event Organizers and Participants" (FOE) policy document was finalized in June 2018 and remains the University's most up-to-date guest speaker policy (McMaster 2018).

McMaster's FOE document includes general principles and goals, as well as specific guidance for the audience members, event organizers, and moderators/ facilitators of campus speaking events. Though a subheading is not included for guest speaker guidance, invited speakers are referenced in the guidelines for event organizers. Event organizers "are responsible for communicating this guidance and the expectations of the University to invited speakers or performers and for securing their agreement to them in advance of the event" (McMaster 2018, 3). Since the document does not include explicit guidelines for invited speakers, it must therefore be inferred that the guidance and expectations to which this line refers are the document's "General Goals and Principles." Within this section, there is no mention of speech restrictions for visiting speakers, however, quite oppositely, the document states that its policies are "intended to be applied without regard for the subject matter or content of any particular speech, performance or event held on McMaster University property" (McMaster 2018, 2). Aside from the legal limitations on free speech outlined on their Freedom of Expression FAQ page, McMaster University guidelines do not include additional speech restrictions for invited speakers.

Though it may seem that McMaster's FOE policy aims to encourage open inquiry through unhindered freedom of expression, these types of open speech policies can have unintended but harmful repercussions. Open speech policies often reinforce unjust social hierarchies, as the voices of the most powerful or privileged are those most likely to be heard. Conversely, dissenting voices, especially those from marginalized groups, tend to be read as insolent and defiant. As Hofmann-Kuroda $(2017,370)$ remarks, "When freedom of speech is framed as a universal right-without regard to the specificities of race, class, and gender-it can in fact work to consolidate the power of the ruling majority and thus reproduce the status quo." University speech policies should reflect the ways that free speech rhetoric is employed to bolster harmful and violent speech that perpetuate systemic oppression. In order to meaningfully consider how open speech policies reinforce unjust social hierarchies, policies should include content-based speech restrictions that go beyond the legal limits on hate speech and refuse platforms for bridging rhetoric.

\section{Concluding Remarks: Why Universities Must Take Responsibility for the Outcomes of Their Policies}

In Canada, the responsibilities of the university are not limited to upholding rigorous academic standards. According to Universities Canada's Statement on Academic Freedom, the institutional responsibility to uphold the principles of academic freedom must be balanced with other ethical duties:

Universities must also ensure that the rights and freedoms of others are respected, and that academic freedom is exercised in a reasonable and responsible manner [...] Faculty members and university leaders have an obligation to ensure that students' human rights are respected and 
that they are encouraged to pursue their education according to the principles of academic freedom. (Universities Canada 2011)

In order to uphold their commitment to human rights, university policies should reflect the potential impact of guest speaker events. Even if universities claim that providing a platform for a particular speaker does not equate to approval of that speaker's views, the offer of a platform speaks for itself. The university is a respected institution that plays a role in certifying expertise; as such, the very fact of invitation signals credibility and epistemic significance (Levy 2019, 11). The authority afforded by a university platform amplifies the impact of a given message. Much in the way that the academic integrity of an invited speaker contributes to the university's broader intellectual culture, an invited speaker's covert attacks on equality functions to re-inscribe broader oppressive structures. It is therefore not enough to only refuse platforms to those who make overt calls for violence or hate speech — taking inclusivity seriously requires a more refined policy. University policies should additionally refuse platforms to speech that normalizes acts of violence, in recognition of how open speech policies bolster the status quo, including unjust social hierarchies. Resisting oppressive heteroactivist and alt-right ideologies requires a recognition of how free speech rhetoric is co-opted to advance covert attacks against marginalized groups. By introducing nuanced restrictions to guest speaker policies, it is possible to balance the values of academic freedom, free expression, and the safety of university community members.

\section{References}

Barrow, Robin. 2009. "Academic Freedom: Its Nature, Extent and Value." British Journal of Educational Studies 57, no. 2: 178-190. https:// doi.org/10.1111/j.1467-8527.2009.00433.x.

BBC News. 2017. "Milo Yiannopoulos: Who is the Alt-Right Writer and Provocateur?" BBC News, February 21, 2017. https://www.bbc.com/news/ world-us-canada-39026870.

Beatty, Dave. 2017. "McMaster Debate with Controversial Professor Jordan Peterson Disrupted by Activists." CBC News, March 19, 2017. https:// www.cbc.ca/news/canada/hamilton/mcmaster-debatewith-controversial-professor-jordan-petersondisrupted-by-activists-1.4031843.

Ben-Porath, Sigal. 2019. "Free Speech on Campus Means Universities Must Protect the Dignity of All Students." The Conversation, October 10, 2017. https://theconversation.com/free-speech-on-campusmeans-universities-must-protect-the-dignity-of-allstudents-124526.

Brean, Joseph. 2019. "How Faith Goldy Became the Most Dangerous Woman Not on the Campaign Trail.” The National Post, September 17, 2019. https:// nationalpost.com/news/politics/election-2019/howfaith-goldy-became-the-most-dangerous-woman-noton-the-campaign-trail.

Ceci, Stephen J. and Wendy M. Williams. 2018.

"Who Decides What is Acceptable Speech on Campus? Why Restricting Free Speech is Not the Answer." Perspectives on Psychological Science 13, no. 3: 299-323. https://doi.org/ $10.1177 / 1745691618767324$.

Criminal Code, RSC 1985, c C-46, s 319.

Daley, Dean. 2017. "Misgendering, a Not So Silent Killer." The Chronicle, March 24, 2017. https:// chronicle.durhamcollege.ca/2017/03/misgenderingnot-silent-killer/. 
Danuta Walters, Suzanna. 2017. "Academe's Poisonous Call-Out Culture." The Chronicle of Higher Education, May 5, 2017.

https://www.chronicle.com/article/Academe-s-

Poisonous-Call-Out/240016.

Dearden, Lizzie. 2017. "Donald Trump Threatens to Withdraw Federal Funds from Berkeley University After Breitbart Editor Talk Cancelled." The Independent, February 2, 2017. https:// www.independent.co.uk/news/world/americas/donaldtrump-breitbart-news-remove-federal-fundingberkeley-university-california-milo-yiannopoulosa7558946.html.

Dennis, Riley J. 2017. "Misgendering Trans People is an Act of Violence | Riley J. Dennis." January 5, 2017. YouTube video. https://www.youtube.com/watch?v=gu5gYxXHoA\&feature=youtu.be.

Dunt, Ian. 2015. "Safe Space or Free Speech? The Crisis Around Debate at UK Universities." The Guardian, February 6, 2015. https:// www.theguardian.com/education/2015/feb/06/safespace-or-free-speech-crisis-debate-uk-universities.

Hastie, Scott. 2016. "Alt-Right Posters Appear on Campus." The Silhouette, November 21, 2016. https:// www.thesil.ca/alt-right-posters-appear-campus.

Heinze, Eric. 2018. "No-Platforming and Safe Spaces: Should Universities Censor More (or Less) Speech than the Law Requires?" Croatian Political Science Review 55, no. 4: 79-108. https://doi.org/10.20901/ pm.55.4.04.

Hofmann-Kuroda, Lisa. 2017. "Free speech and the Alt-Right." Qui Parle: Critical Humanities and Social Sciences 26, no. 2: 369-382. https://www.muse.jhu.edu/ article/689614.

Krug, Etienne G., James A. Mercy, Linda L. Dahlberg, Anthony B. Zwi, and Rafael Lozano. 2002. "The World Report on Violence and Health." Geneva: World Health Organization.
Lam, Peggy and Kate Bueckert. 2018. "Ontario University Won't Stop Talk by Anti-Immigration Speaker Faith Goldy." CBC News, March 20, 2018. https://www.cbc.ca/news/canada/kitchener-waterloo/ faith-goldy-wilfrid-laurier-university-lindsay-shepherd1.4584066 .

Levy, Neil. 2019. "No-Platforming and Higher-Order Evidence, or Anti-Anti-No-Platforming." Journal of the American Philosophical Association 5, no. 4: 487-502. https://doi.org/10.1017/apa.2019.29.

Lynskey, Dorian. 2018. "How Dangerous is Jordan Peterson, the Rightwing Professor Who 'Hit a Hornets' Nest?"' The Guardian, February 7, 2018. https://www.theguardian.com/science/2018/feb/07/ how-dangerous-is-jordan-b-peterson-the-rightwingprofessor-who-hit-a-hornets-nest.

Lyons, Matthew N. 2017. "Ctrl-Alt-Delete: The Origins and Ideology of the Alternative Right." Political Research Associates, January 20. Accessed May 15, 2019.

McKenzie, Lindsay, Adam Harris, and Fernanda Zamudio-Suaréz. 2017. "A Journal Article Provoked a Schism in Philosophy. Now the Rifts are Deepening." The Chronicle of Higher Education, May 6, 2017. https://www.chronicle.com/article/A-Journal-ArticleProvoked-a/240021.

McLemore, Kevin A. 2015. "Experiences with Misgendering: Identity Misclassification of Transgender Spectrum Individuals." Self and Identity 14, no. 1: $51-74$.

McMaster University. n.d. "Freedom of Expression: Frequently Asked Questions.” Accessed January 20, 2020. https://president.mcmaster.ca/frequently-askedquestions/.

. 2018. "Freedom of Expression, Protest and Dissent: Guidance for Event Organizers and Participants." Policies, Procedures and Guidelines. Last modified June 8, 2019. http://secretariat.mcmaster.ca/ university-policies-procedures-guidelines/. 
Murphy, Jessica. 2016. "Toronto Professor Jordan Peterson Takes on Gender-Neutral Pronouns." BBC, November 16, 2016. https://www.bbc.com/news/ world-us-canada-37875695.

Nash, Catherine J., Andrew Gorman-Murray, and Kath Browne. 2019. "Geographies of Intransigence: Freedom of Speech and Heteroactivist Resistances in Canada, Great Britain and Australia." Social \& Cultural Geography 1-21. https://doi.org/ 10.1080/14649365.2019.1652929.

O'Keefe, Theresa. 2016. "Making Feminist Sense of No-Platforming." Feminist Review 113, no. 1: 85-92. https://doi.org/10.1057/fr.2016.7.

Oliver, Kelly. 2017. "If This is Feminism..." The Philosophical Salon, May 8, 2017. https:// web.archive.org/web/20170509035813/http:// thephilosophicalsalon.com/if-this-is-feminism-itsbeen-hijacked-by-the-thought-police/.

Paradkar, Shree. 2018. "Faith Goldy's Talk at Wilfred Laurier was Cancelled. And a Damn Good Thing, Too." The Star, March 21, 2018. https:// www.thestar.com/opinion/star-columnists/2018/03/21/ faith-goldys-talk-at-wilfred-laurier-was-cancelled-anda-damn-good-thing-too.html.

Picazo, Alheli. 2017. "How the Alt-Right Weaponized Free Speech.” Maclean's, May 1, 2017. https:// www.macleans.ca/opinion/how-the-alt-rightweaponized-free-speech/.

Peterson, Jordan. 2016. “'I'm Not a Bigot' Meet the U of T Prof Who Refuses to Use Genderless Pronouns." Interview by Carol Off. Canadian Broadcasting Corporation, September 30, 2016. https://www.cbc.ca/ radio/asithappens/as-it-happens-friday-edition$1.3786140 / \mathrm{i}-\mathrm{m}$-not-a-bigot-meet-the-u-of-t-prof-whorefuses-to-use-genderless-pronouns-1.3786144.

. 2018. "Jordan Peterson on Why He Refuses to Use Special Pronouns for Transgender People - LBC.” Interview by Maajid Nawaz. LBC, May 22, 2018. YouTube video. https://www.youtube.com/watch? $\mathrm{v}=$ s_UbmaZQx74.
Scott, Joan Wallace. 2020. "The Right has Weaponized Free Speech.” Academe Blog, January 10, 2020. https://academeblog.org/2020/01/10/theright-has-weaponized-free-speech/.

Simpson, Robert Mark. 2013. "Dignity, Harm, and Hate Speech." Law and Philosophy 32, no. 6: 701728. https://doi.org/10.1007/s10982-012-9164-z.

Simpson, Robert Mark and Amia Srinivasan. 2018. "No Platforming." In Academic Freedom, edited by Jennifer Lackey, 186-209. Oxford: Oxford University Press.

Singal, Jessie. 2017. "This is What a Modern-Day Witch Hunt Looks Like.” New York Magazine, May 2, 2017.

https://nymag.com/intelligencer/2017/05/ transracialism-article-controversy.html.

The Canadian Anti-Hate Network. 2018. "Who is Faith Goldy?” Last modified October 18, 2018. https://www.antihate.ca/who_is_faith_goldy.

The Canadian Mental Health Association. n.d. "Lesbian, Gay, Bisexual, Trans \& Queer Identified People and Mental Health." Accessed November 18, 2019. https://ontario.cmha.ca/documents/lesbiangay-bisexual-trans-queer-identified-people-andmental-health/.

Tuvel, Rebecca. 2017. "In Defense of Transracialism." Hypatia 32, no. 2: 263-278.

https://doi.org/10.1111/hypa.12327.

Universities Canada. 2011. "Statement on Academic Freedom." Last modified October 25, 2011. https:// www.univcan.ca/media-room/media-releases/ statement-on-academic-freedom/.

Weinberg, Justin. 2017a. "Philosopher's Article on Transracialism Sparks Controversy (Updated with Response from the Author." Daily Nous, May 1, 2017. http://dailynous.com/2017/05/01/ philosophers-article-transracialism-sparkscontroversy/. 
2017b. "Hypatia's Editor and Its Board

President Defend Publication of Tuvel Article.” Daily

Nous, May 6, 2017.

http://dailynous.com/2017/05/06/hypatias-editor-

board-president-defend-publication-tuvel-article/.

Zhou, Steven. 2017. "Canadian Campuses See an

Alarming Rise in Right-Wing Populism.” CBC News.

January 15.

https://www.cbc.ca/news/canada/manitoba/opinion-

campus-right-wing-populism-1.3932742.

Zine, Jasmine. 2018. "The Alt-Right and the

Weaponization of Free Speech on Campus." Academic

Matters, Fall 2018, 26-28. 